\title{
Systemic Inflammatory Markers as a Prognostic Factor in Parotid Gland Tumors
}

\author{
Orhan Tunç (D), Burhanettin Gönüldaş (D), Muzaffer Kanlıkama (D) \\ Department of Otorhinolaryngology, Gaziantep University, Gaziantep, Turkey \\ ORCID iDs of the authors: O.T. 0000-000I-7764-II38; B.G. 0000-0003-0I33-453I; M.K. 0000-0002-3537-7778.
}

Cite this article as: Tunç O, Gönüldaş B, Kanlıkama M. Systemic Inflammatory Markers as a Prognostic Factor in Parotid Gland Tumors. Cyprus J Med Sci 2021; 6(2): 171-176.

BACKGROUND/AIMS

In this study, it was aimed to evaluate systemic inflammatory markers as prognostic factors in patients with parotid gland tumors.

\section{MATERIAL and METHODS}

Between 2014and2019, retrospective analysis of 181 patients who applied to Otorhinolaryngology Clinic and operated due to parotid gland tumor was performed. Additionally, 63 patients without tumor were included in the study as a control group. According to the post-operative histopathological diagnosis, it was divided into two groups as patients with benign and malignant tumors. The patients' age, gender, pre-operative blood tests, neutrophil-lymphocyte ratio(NLR), platelet-lymphocyte ratio(PLR), MPV-platelet ratio(MPVPR), MPV-lymphocyte ratio(MPVLR) and Systemic inflammatory index(SII) parameters calculated.

\section{RESULTS}

RBC, hemoglobin, hematocrit and lymphocyte levels were statistically significantly lower in patients with malign tumor compared to other groups. In addition, compared to benign tumor group, NLR, PLR and SIl levels significantly increased and MPVLR level significantly decreased in patients with malign tumor. Consequently, according to ROC analysis for malign tumor, RDW, lymphocyte, NLR, PLR, MPVLR and SIl were significant prognostic factors $(P=.036, P=.002, P=.033, P=.004, P=.001, P=.049$, respectively).

\section{CONCLUSION}

RDW, lymphocyte, NLR, PLR, MPVLR and SIl parameters, which are fast, cheap and easy to use, can be used in the differential diagnosis of benign and malignant masses in patients with parotid gland tumors.

Keywords: Parotid gland tumors, red cell distribution width, neutrophil-lymphocyte ratio, platelet-lymphocyte ratio, systemic inflammatory index

\section{INTRODUCTION}

Salivary gland tumors (SGTs) constitute about 5-10\% of all head and neck tumors, and approximately $80-85 \%$ of these tumors originate from the parotid gland. ${ }^{1,2}$ Treatment of parotid tumors is primarily surgery. However, the planning of surgery varies depending on the histopathology and local spread of the tumor. Therefore, it is vital to distinguish whether the lesions are benign or malignant in the preoperative period. Fine needle aspiration biopsy (FNAB) is the most commonly used diagnostic method today. FNAB has over $95 \%$ sensitivity in the separation of tumor and nontumor pathologies, while $90 \%$ in the benign/malignant distinction.' Parotid tumors contain a large group of tumors with similar clinical and histopathological features. In these tumors, cystic degeneration is also frequently encountered. It is very difficult to make a definitive diagnosis in aspirates containing cystic rash.' An experienced cytopathologist is required for a definitive diagnosis.

In recent years, the number of studies evaluating the relationship between cancer and immune system has increased considerably. Epithelial inflammation is an important and diffuse pathological event that occurs alone or as a result of neoplasia. ${ }^{3}$ First, inflammatory cells acts as a defense mechanism to prevent the formation of tumors task; however, preventing apoptosis may facilitate tumor proliferation and metastasis secondary to angiogenesis and DNA damage as a result of chronic inflammation. ${ }^{4,5}$ Many researchers have reported that systemic inflammatory markers are important 
independent predictive markers in the diagnosis and prognosis of head and neck cancers, based on the idea that inflammation contributes to cancer onset and progression. ${ }^{6-12}$ We aimed to evaluate the importance of preoperative systemic inflammatory markers (red cell distribution width [RDW], platelet, mean platelet volume [MPV], neutrophil-lymphocyte ratio [NLR], platelet-lymphocyte ratio [PLR], MPV-platelet ratio [MPVPR], $M P V$-lymphocyte ratio [MPVLR], and systemic inflammatory index [SII]) as a prognostic factor in the differential diagnosis of benign and malignant parotid masses in our clinic.

\section{MATERIALS and METHODS}

In our study, between 2014 and 2019, retrospective analysis of I8I patients who applied to University Research Hospital Otorhinolaryngology Clinic and operated on for parotid tumor was performed. In addition, as a control group, 63 patients without cancer were included in the study. Patients with active infection, hematological diseases, second primary cancer, and chronic inflammatory diseases, such as systemic lupus erythematosus and missing data, were excluded from the study. The study was approved by Gaziantep University Clinical Research Ethics Committee (2020/I34). Written informed consent was obtained from the patients who participated in this study.

The patients' ages, genders, and preoperative blood tests (one day before surgery), and pathology results (tumor type, benign or malign) were obtained from the patients' files. In addition, NLR, PLR, MPVPR, MPVLR, the systematic inflammatory index (SII) values were calculated and recorded. The following parameters were calculated from the hemogram results performed at the preoperative stage.

The NLR was calculated by dividing the neutrophil count by the lymphocyte count. PLR was found by dividing platelet count by lymphocyte count. MPVPR was found by dividing the number of MPV by the number of platelets. MPVLR was found by dividing the number of MPV by lymphocyte count. The SII was found by multiplying neutrophil count and PLR value.

The tumor classification of the patients was made according to the TNM classification determined by The American Joint Committee on Cancer, which was modified in 2017. The stage of the tumor and lymph node involvement were evaluated based

\section{Main Points}

- Compared to benign tumor group, NLR, PLR, and SII levels significantly increased and MPVLR level significantly decreased in patients with malign tumor.

- According to the results of ROC analysis in patients with malign tumor, sensitivity $60.7 \%$ and specificity $54.2 \%$ for RDW $(P=.036)$, sensitivity $41.0 \%$ and specificity $40.8 \%$ for lymphocyte $(P=.002)$, sensitivity $59.0 \%$ and specificity $56.7 \%$ for $\operatorname{NLR}(P=.033)$, sensitivity $59.0 \%$ and specificity $56.7 \%$ for PLR $(P=.004)$, sensitivity $37.7 \%$ and specificity $35.0 \%$ for MPVLR $(P=.00 \mathrm{l})$ were found.

- The risk factors found to be significantly related to differentiation in the regression analysis involved lymphocyte, NLR, PLR, and MPVLR, while the effect of age for differentiating malign tumor from benign tumor in multiple regression analysis was not statistically significant. on histopathological evaluation. Analyses of all samples were performed on Sysmex XN-9100TM (Kobe, Japan) hematological auto-analyzer devices.

\section{Statistical Analysis}

All analyzes were done using Statistical Package for the Social Sciences (SPSS) version 25 (IBM SPSS Corp; Armonk, NY, USA). $P$ values less than .05 were considered significant. The normality control of the data was done with the Shapiro-Wilk test. Student's t test was used for comparing the means of normally distributed parameters, and Mann-Whitney $U$ test was used for the comparison of parameters that did not conform to normal distribution. In multiple comparisons, Kruskal-Wallis variance analysis was used. Descriptive statistics were expressed with odds ratio and $95 \%$ confidence intervals. ROC analysis was used to determine the cut-off point, the area under the curve (AUC), the sensitivity (sensitivity), and the specificity (specificity) of the data. Multivariate logistic regression analysis performed to distinguish benign from malignant tumor in terms of factors age, MPV, platelet, RDW, lymphocyte, NLR, PLR, MPVPR, MPVLR, and SII.

\section{RESULTS}

Comparison of laboratory and socio-demographic findings between the groups of patient and control is shown in Table I. The mean age of the patients was $49.59 \pm$ 15.7. In the control group, the mean age was $42.76 \pm$ I3.I. There was a statistically significant difference between the groups in terms of age $(P=$ .002). Compared to the control group, WBC, MCV, MCH, RDW, and neutrophil levels were statistically significantly higher in the patient group $(P=.027, P=.007, P=.004, P=.032, P=$ .033, respectively). Hemoglobin and hematocrit levels were statistically significantly lower in the patient group compared to the control group ( $P=.020, P=.003$, respectively). There was not any statistical significance between the groups in terms of other parameters (Table I).

Comparison of laboratory results according to tumor status is shown in Table 2. There was a statistically significant difference between groups in terms of WBC, RBC, hemoglobin, hematocrit, $\mathrm{MCV}, \mathrm{MCH}, \mathrm{RDW}$, platelet, and lymphocyte levels $(P=.040, P<.001, P=.002, P<.001, P=.028, P=.017, P=.012$, and $P=.004$, respectively). WBC, MCV, MCH, and lymphocyte levels were statistically significantly higher in patients with benign tumor compared to control. RBC, hemoglobin, hematocrit, and lymphocyte levels were statistically significantly lower in patients with malign tumor compared to other groups. However, there was statistical significance between the groups in terms of NLR, PLR, MPVLR, and SIl parameters $(P=.022, P=$ $.010, P=.003$, and $P=.049$, respectively). In addition, compared to benign tumor group, NLR, PLR, and SIl levels significantly increased and MPVLR level significantly decreased in patients with malign tumor (Table 2).

ROC analysis results in patients with malign tumor are shown in Table 3. According to the results of ROC analysis in patients with malign tumor, sensitivity $47.5 \%$ and specificity $48.3 \%$ for MPV $(P=.448)$. sensitivity $47.5 \%$ and specificity $50.8 \%$ for platelet $(P=.638$ ), sensitivity $60.7 \%$ and specificity $54.2 \%$ for RDW $(P=.036)$, sensitivity $41.0 \%$ and specificity $40.8 \%$ for lymphocyte $(P=.002)$, sensitivity $59.0 \%$ and specificity $56.7 \%$ for NLR $(P=.033)$, sensitivity $59.0 \%$ and specificity $56.7 \%$ for PLR $(P=$ $.004)$, sensitivity $54.1 \%$ and specificity $50.0 \%$ for MPVPR ( $P=$ 
TABLE I. Comparison of Laboratory and Sociodemographic Findings

\begin{tabular}{|c|c|c|c|}
\hline & Patient $(n=18 \mid)$ & Control $(n=63)$ & $P$ value \\
\hline Age (years) & $49.59 \pm 15.7$ & $42.76 \pm 13.1$ & $.002^{*}$ \\
\hline Gender $(n, \%)$ & & & .658 \\
\hline Male & $107(59.1 \%)$ & $35(55.6 \%)$ & \\
\hline WBC $\left(\mathrm{mm}^{-3}\right)$ & $8.20(3.7-13.7)$ & $7.64(3.9-13.8)$ & $.027^{* *}$ \\
\hline $\mathrm{RBC}(\mu \mathrm{L})$ & $5.02 \pm 0.5$ & $5.19 \pm 0.4$ & $.016^{*}$ \\
\hline Hemoglobin $\left(\mathrm{g} \mathrm{dL}^{-1}\right)$ & $14.61 \pm 1.8$ & $14.67 \pm 1.4$ & $.020^{*}$ \\
\hline $\mathrm{MCH}(\mathrm{pg})$ & $29.20(18.6-33.2)$ & $28.60(21.9-31.3)$ & $.004^{* *}$ \\
\hline $\mathrm{MCHC}\left(\mathrm{g} \mathrm{dL}^{-1}\right)$ & $33.44 \pm 1.2$ & $33.14 \pm 1.3$ & $.561^{*}$ \\
\hline RDW (\%) & $13.30(11.5-22.7)$ & $12.90(11.8-17.2)$ & $.032^{*}$ \\
\hline Platelet $\left(\mathrm{mm}^{-3}\right)$ & $270.71 \pm 58.3$ & $268.79 \pm 59.4$ & $.501^{*}$ \\
\hline $\mathrm{MPV}(\mathrm{fL})$ & $10.20(6.8-12.3)$ & $10.40(9.1-13.8)$ & $.049^{* *}$ \\
\hline Neutrophil $\left(\mathrm{mm}^{-3}\right)$ & $4.89(2.0-11.1)$ & $4.17(1.4-8.9)$ & $.033^{* *}$ \\
\hline MPVLR & $4.08(1.2-15.5)$ & $4.48(2.2-9.9)$ & $.150^{* *}$ \\
\hline SII & $498.62(|25.9-27| 4.0)$ & $490.82(163.9-1395.7)$ & $.423^{* *}$ \\
\hline \multicolumn{4}{|c|}{$\begin{array}{l}\text { WBC, white blood cell; RBC, red blood cell; MCV, mean corpuscular volume; MCH, mean corpuscular hemoglobin; RDW, red cell distribution width; MPV, } \\
\text { mean platelet volume; NLR, neutrophil-lymphocyte ratio; PLR, platelet-lymphocyte ratio; MPVPR, MPV-platelet ratio; MPVLR, MPV-lymphocyte ratio; } \\
\text { SII, systemic inflammatory index. } \\
\text { *Student t test. } \\
\text { **Mann-Whitney U test. }\end{array}$} \\
\hline
\end{tabular}

TABLE 2. Comparison of Laboratory Results According to Tumor Status

\begin{tabular}{|c|c|c|c|c|}
\hline & Control $(n=63)$ & Benign $(n=120)$ & Malign $(n=61)$ & $P$ value \\
\hline $\mathrm{RBC}(\mu \mathrm{L})$ & $5.19 \pm 0.4$ & $5.14 \pm 0.5$ & $4.82 \pm 0.5^{\dagger}$ & $<.001$ \\
\hline Hemoglobin $\left(\mathrm{g} \mathrm{dL}^{-1}\right)$ & $14.67 \pm 1.4$ & $14.92 \pm 1.7$ & $13.99 \pm 1.7^{\dagger}$ & .002 \\
\hline Hematocrit (\%) & $44.2 \pm 3.7$ & $44.6 \pm 4.5$ & $41.6 \pm 5.0^{+}$ & $<.001$ \\
\hline$M C \vee(f L)$ & $85.20(69.6-94.9)$ & $87.50(65.7-97.5)^{*}$ & $86.90(61.2-98.3)^{*}$ & .028 \\
\hline $\mathrm{MCH}(p g)$ & $28.60(21.9-31.3)$ & $29.25(20.4-33.2)^{*}$ & $29.00(18.6-32.9)^{*}$ & .017 \\
\hline $\mathrm{MCHC}\left(\mathrm{g} \mathrm{dL}^{-1}\right)$ & $33.14 \pm 1.3$ & $33.38 \pm 1.3$ & $33.55 \pm 1.1$ & .216 \\
\hline$M P \vee(f L)$ & $10.40(9.1-13.8)$ & $10.20(7.7-12.3)$ & $10.10(6.8-12.3)$ & .305 \\
\hline Neutrophil $\left(\mathrm{mm}^{-3}\right)$ & $4.17(1.4-8.9)$ & $4.95(2.1-10.9)$ & $4.83(2.0-11.1)$ & .103 \\
\hline Lymphocyte $\left(\mathrm{mm}^{-3}\right)$ & $2.34(1.3-4.7)$ & $2.62(0.7-5.7)^{*}$ & $2.31(0.7-5.5)^{\dagger}$ & .004 \\
\hline NLR & $1.89(0.6-5.0)$ & $1.82(0.8-8.6)$ & $2.00(0.9-14.7)^{\dagger}$ & .022 \\
\hline PLR & $112.06(39.3-217.7)$ & I0I.7| (46.8-374.I) & $120.58(38 .|-3| 8.6)^{\ddagger}$ & .010 \\
\hline MPVPR & $0.037(0.02-0.08)$ & $0.038(0.02-0.06)$ & $0.038(0.01-0.10)$ & .876 \\
\hline
\end{tabular}

.888), sensitivity $37.7 \%$ and specificity $35.0 \%$ for MPVLR ( $P=$ .001 ), sensitivity $55.7 \%$ and specificity $56.7 \%$ for SII were found. The cut-off point for these values were $<10.15,>263.5,>13.25$, $<2.40,>1.92,>106.9,>0.037,<3.91$, and $>505.8$, respectively. As a result, according to $\mathrm{ROC}$ analysis for malign tumor, MPV, platelet, and MPVPR were not found to be a prognostic factor, although the RDW, lymphocyte, NLR, PLR, MPVLR, and SII were significant prognostic factors (Table 3 and Figure I).

Multivariate logistic regression analysis performed to distinguish benign from malignant tumor is shown in Table 4. The risk factors found to be significantly related to differentiation in the 


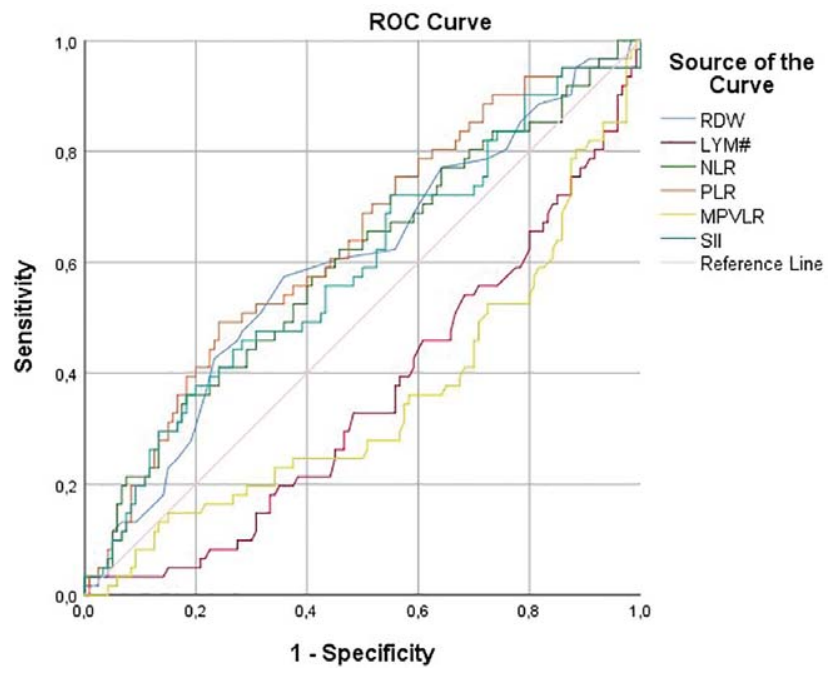

Figure I. ROC analysis of RDW, lymphocyte, NLR, PLR, MPVLR, and SII (RDW, red cell distribution width; NLR, neutrophil-lymphocyte ratio; PLR, platelet-lymphocyte ratio; MPVLR, mean platelet volume-lymphocyte ratio; SII, systemic inflammatory index)

regression analysis involved lymphocyte, NLR, PLR, and MPVLR while the effect of age for differentiating malign tumor from benign tumor in multivariate logistic regression analysis was not statistically significant (Table 4).

\section{DISCUSSION}

In our study, WBC, hemoglobin, RBC, hematocrit, MPV, RDW, $\mathrm{MCV}, \mathrm{MCH}$, and neutrophil levels were statistically significant in parotid tumor patients compared to healthy individuals. However, compared to benign tumor group, NLR, PLR, and SII levels significantly increased and MPVLR level significantly decreased in patients with malign tumor. As a result, according to ROC analysis for malign tumor, MPV, platelet, and MPVPR were not found to be a prognostic factor, even though the RDW, lymphocyte, NLR, PLR, MPVLR, and SIl were significant prognostic factors. In addition, the risk factors found to be significantly related to differentiating malign tumor from benign tumor in the regression analysis included lymphocyte, NLR, PLR, and MPVLR.

MPV was an early marker of activated platelets. Greater platelet reactivity has more than smaller ones. ${ }^{13}$ The relationship between MPV and cancer has been researched in different cancer types. ${ }^{14,15}$ It has been shown that thyroid papillary carcinomas have higher MPV levels than benign goiter patients and the control group, and MPV levels decrease after surgical treatment. ${ }^{15}$ In a study by Fu et al. ${ }^{16}$ in 216 laryngeal cancer patients, they showed that MPV was significantly lower in laryngeal cancer patients compared with control. It is also stated that MPV is one of the independent risk factors for distinguishing malignant laryngeal tumor from benign laryngeal tumor. ${ }^{16}$ Eryilmaz et al. ${ }^{17}$ reported that MPV levels of the patients were significantly high in their study on 96 head and neck cancer patients. In contrast to, MPV levels were statistically significantly lower in the parotid tumor group compared to the control group in our study.

RDW is a parameter that shows the degree of heterogeneity of erythrocyte volume. Its level increases in diseases, such as venous thromboembolism, diabetes, cardiovascular disease, and cancer. ${ }^{18}$ It is stated that RDW is a prognostic factor in various types of cancer, such as lung, breast, esophagus, brain, kidney, stomach, colon, pancreas, prostate, multiple myeloma,

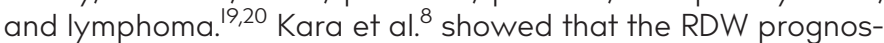
tic effects in 103 larynx carcinoma patients. In our study, RDW levels were statistically significantly higher in the patient with malign tumor group compared to control group. As a result, according to ROC analysis for malign tumor, it was determined that RDW is one of the prognostic factors.

Lymphocytes have a potent antitumor response of cellular immune and are important immune system components. ${ }^{21} \mathrm{Com}-$ pared to neutrophils, lymphocytes supply host defense against tumors; hence, lymphocyte increase is related to a better prognosis. ${ }^{22}$ On the contrary, lymphopenia shows impaired cellular immunity against tumors and is related to poor prognosis. ${ }^{23}$ In our study, lymphocyte levels were statistically significantly lower in patients with malign tumor compared to control and benign tumor group. In addition, as a result according to ROC analysis for malign tumor, it was determined that lymphocyte is one of the important prognostic factors.

In the study of Damar et al. ${ }^{2}$ on 182 patients covering all SGTs, they reported that high NLR and low lymphocyte count can be used to distinguish malignant tumors from benign tumors. The PLR was also presented as prognostic value in various different tumor types (tongue cancer, oral cancer, etc.). ${ }^{24,25}$ In the study of Ekici and Kuran ${ }^{26}$ on 134 patients, they stated that NLR and PLR can be used in the differential diagnosis of benign and malignant masses in parotid gland tumors patients. In the study of Kuzucu et al. ${ }^{10}$ in 145 patients with parotid tumors, they stated that preoperative PLR and NLR values are higher malignant parotid tumors patients than benign parotid tumor patients. In our study, there was statistical significance between the groups in terms of PLR and NLR parameters. In addition, compared to benign tumor group, NLR and PLR levels significantly increased in patients with malign tumor. However, according to the results of $\mathrm{ROC}$ analysis in patients with malign tumor, the RDW, PLR, and NLR were significant prognostic factors.

Deveci and Sürmeli ${ }^{7}$ reported that high SIl values were associated with increased perineural/lymphovascular invasion and extranodal involvement. Ekici and Kuran ${ }^{26}$ did not find a statistically significant difference in their study on 134 patients with parotid gland tumors, although the SII value was higher in the malignant tumor group. In our study, compared to benign tumor group, SIl levels significantly increased in patients with malign tumor. However, as a result according to ROC analysis for malign tumor, it was determined that SII is one of the important prognostic factors.

Recently, the MPVLR was shown as one of the complete blood count parameters. It was first shown by Kuzucu et al. ${ }^{10}$ in patients with myocardial infarction and diabetes as a potential prognostic marker in 2016. In the study of Sut et al. ${ }^{27}$ in 78 patients with breast cancer, compared to control, they reported that MPVLR, NLR, and PLR levels were significantly higher in patients with breast cancer. In addition, a significant association was found between NLR, PLR but not MPVLR and low dietary polyphenol intake in breast cancer patients. ${ }^{27}$ In our study, NLR, PLR, and SIl levels significantly increased and MPVLR 


\begin{tabular}{|c|c|c|c|c|c|}
\hline & Cut-off & Sensitivity & Specificity & $\operatorname{AUC}(95 \% \mathrm{Cl})$ & $P$ value \\
\hline$M P \vee(f L)$ & $<10.15$ & $47.5 \%$ & $48.3 \%$ & $0.465(0.37 \mid-0.560)$ & .448 \\
\hline RDW (\%) & $>13.25$ & $60.7 \%$ & $54.2 \%$ & $0.596(0.507-0.684)$ & .036 \\
\hline Lymphocyte $\left(\mathrm{mm}^{-3}\right)$ & $<2.40$ & $41.0 \%$ & $40.8 \%$ & $0.358(0.274-0.442)$ & .002 \\
\hline NLR & $>1.92$ & $59.0 \%$ & $56.7 \%$ & $0.597(0.508-0.686)$ & .033 \\
\hline PLR & $>106.9$ & $59.0 \%$ & $56.7 \%$ & $0.631(0.545-0.717)$ & .004 \\
\hline SII & $>505.8$ & $55.7 \%$ & $56.7 \%$ & $0.589(0.499-0.678)$ & .051 \\
\hline
\end{tabular}

AUC, area under the curve; MPV, mean platelet volume; RDW, red cell distribution width; NLR, neutrophil-lymphocyte ratio; PLR, platelet-lymphocyte ratio; MPVPR, MPV-platelet ratio; MPVLR, MPV-lymphocyte ratio; SIl, systemic inflammatory index.

\begin{tabular}{|c|c|c|c|}
\hline & $\beta$ & OR $(95 \% \mathrm{Cl})$ & $P$ value \\
\hline$M P \vee(f L)$ & -0.267 & $0.766(0.534-1.097)$ & .145 \\
\hline Platelet $\left(\mathrm{mm}^{-3}\right)$ & -0.002 & $0.998(0.992-1.004)$ & .589 \\
\hline RDW (\%) & 0.049 & $1.050(0.776-1.422)$ & .176 \\
\hline Lymphocyte $\left(\mathrm{mm}^{-3}\right)$ & -0.566 & $0.568(0.369-0.873)$ & .010 \\
\hline MPVPR & 0.001 & $0.011(0.008-0.014)$ & .398 \\
\hline MPVLR & -0.279 & $0.757(0.597-0.959)$ & .021 \\
\hline SII & 0.001 & $1.001(1.000-1.002)$ & .079 \\
\hline
\end{tabular}

level significantly decreased in patients with malign tumor. As a result according to $\mathrm{ROC}$ analysis for malign tumor, RDW, lymphocyte, NLR, PLR, MPVLR, and SII were significant prognostic factors. However, as a result of multivariate logistic regression analysis, the risk factors found to be significantly related to differentiation in the regression analysis, including lymphocyte, NLR, PLR, and MPVLR used for differentiating malign tumor from benign tumor. According to the literature knowledge, this is the first research to examine the relation between MPVLR and in patients with parotid cancer. We consider that reduced MPVLR may reflect an impaired interaction between tumor cells, blood platelets, and lymphocyte dependent immune response.

Studies in the literature report that most of the systemic inflammatory markers change with age (e.g., RDW decreases, MCV, NLR increase) in a healthy population. ${ }^{28-32}$ In our study, although there was a significant difference between the patient group and the healthy group in terms of age, the effect of age for differentiating malign tumor from benign tumor in multivariate logistic regression analysis was not statistically significant.

As limitations in our study, our study is a single center and retrospective study. The small sample size and age differences were other limitations. Moreover, multicenter and prospective studies could be planned to backup these preliminary results. Compared to other studies in the literature, $2,8,17,26$ the strengths of our study, our sample was larger and our results were supported by a logistic regression analysis.

In conclusion, as far as we know, this study is the first study to evaluate different numbers and rates of leukocytes (especially MPVLR) together before surgery in patients with benign and malign parotid gland tumors. These parameters which are cheap and easy can be used as a potential prognosis factor in patients with parotid tumors. Our results propound that the combination of RDW, lymphocyte, NLR, PLR, and MPVLR could be utilized as a potential inflammatory marker in patients to differentiate benign from malignant parotid gland tumors. We think that these values should be defined in laboratory devices and added to blood results in order to facilitate the clinician's work. However, new prospective researches with a larger group of patients are needed to determine the reference intervals of these values and to use them as prognostic factors.

Ethics Committee Approval: Ethical committee approval was received from the Gaziantep University Clinical Research Ethics Committee (2020/134).

Informed Consent: Informed consent was obtained from all participants who participated in this study.

Peer-review: Externally peer-reviewed.

Author Contributions: Concept - O.T, B.G.; Design - O.T., B.G., M.K.; Supervision - O.T., M.K.; Resource - O.T., B.G.; Materials - O.T., M.K.; Data Collection and/or Processing - O.T., B.G.; Analysis and/or 
Interpretation - O.T., M.K.; Literature Search - O.T., B.G., M.K.; Writing O.T., B.G., M.K.; Critical Reviews - O.T., M.K.

Conflict of Interest: The authors have no conflicts of interest to declare.

Financial Disclosure: The authors declared that this study has received no financial support.

\section{REFERENCES}

I. Garrett SL, Trott K, Sebastiano C, et al. Sensitivity of fine-needle aspiration and imaging modalities in the diagnosis of low-grade mucoepidermoid carcinoma of the parotid gland. Ann Otol Rhinol Laryngol. 2019;128(8):755-759. [CrossRef]

2. Damar $M$, Dinc $A E$, Erdem $D$, et al. Pretreatment neutrophillymphocyte ratio in salivary gland tumors is associated with malignancy. Otolaryngol Head Neck Surg. 2016;155(6):988-996. [CrossRef]

3. Tsai YD, Wang CP, Chen CY, et al. Pretreatment circulating monocyte count associated with poor prognosis in patients with oral cavity cancer. Head Neck. 2014;36(7):947-953. [CrossRef]

4. Coussens LM, Werb Z. Inflammation and cancer. Nature. 2002;420(6917):860-867. [CrossRef]

5. Jaiswal M, LaRusso NF, Burgart LJ, Gores GJ. Inflammatory cytokines induce DNA damage and inhibit DNA repair in cholangiocarcinoma cells by a nitric oxide-dependent mechanism. Cancer Res. 2000;60(I):184-190.

6. Chen L, Zeng $H$, Yang J, et al. Survival and prognostic analysis of preoperative inflammatory markers in patients undergoing surgical resection for laryngeal squamous cell carcinoma. BMC Cancer. 2018;18(I):816. [CrossRef]

7. Deveci i, Sürmeli M. Correlation of systemic immune-inflammation index and neutrophil-to-lymphocyte ratio with histopathological findings in patients with tongue cancer. Med $J$ Haydarpaşa Numune Train Res Hosp. 2018;58(3):122-127.

8. Kara M, Uysal S, Altinisik U, Cevizci S, Guclu O, Derekoy FS. The pre-treatment neutrophil-to-lymphocyte ratio, platelet-to-lymphocyte ratio, and red cell distribution width predict prognosis in patients with laryngeal carcinoma. Eur Arch Otorhinolaryngol. 2017;274(I):535-542. [CrossRef]

9. Kum RO, Ozcan M, Baklaci D, et al. Elevated neutrophil-to-lymphocyte ratio in squamous cell carcinoma of larynx compared to benign and precancerous laryngeal lesions. Asian Pac J Cancer Prev. 2014;15(17):735I-7355. [CrossRef]

10. Kuzucu I, Guler I, Kum RO, Baklaci D, Ozcan M. Increased neutrophil lymphocyte ratio and platelet lymphocyte ratio in malignant parotid tumors. Braz J Otorhinolaryngol. 2020;86(I):I05-II0. [CrossRef]

II. Rachidi S, Wallace K, Wrangle JM, Day TA, Alberg AJ, Li Z. Neutrophil-to-lymphocyte ratio and overall survival in all sites of head and neck squamous cell carcinoma. Head Neck. 2015;38(Suppl. I):EI068-EI074. [CrossRef]

12. Sefil F, Ulutas KT, Dokuyucu $R$, et al. Investigation of neutrophil lymphocyte ratio and blood glucose regulation in patients with type 2 diabetes mellitus. J Int Med Res. 2014;42(2):58I-588. [CrossRef]

13. Mangalpally KK, Siqueiros-Garcia A, Vaduganathan M, Dong JF, Kleiman NS, Guthikonda S. Platelet activation patterns in platelet size sub-populations: Differential responses to aspirin in vitro. $J$ Thromb Thrombolysis. 2010;30(3):251-262. [CrossRef]

14. Afsar CU, Gunaldi M, Kum P, et al. Pancreatic carcinoma, thrombosis and mean platelet volume: Single center experience from the southeast region of Turkey. Asian Pac J Cancer Prev. 20|4;|5(21):9|43-9|46. [CrossRef]
15. Baldane S, Ipekci SH, Sozen M, Kebapcilar L. Mean platelet volume could be a possible biomarker for papillary thyroid carcinomas. Asian Pac J Cancer Prev. 2015;16(7):2671-2674. [CrossRef]

16. Fu S, Liu L, Zhang X, Liu ZP, Wang RT. Platelet indices in laryngeal cancer. Cancer Biomark. 2018;2I(3):675-680. [CrossRef]

17. Eryilmaz A, Basal Y, Omurlu IK. Can head and neck cancers be detected with mean platelet volume? Asian Pac J Cancer Prev. 2015;16(I6):7045-7047. [CrossRef]

18. Salvagno GL, Sanchis-Gomar F, Picanza A, Lippi G. Red blood cell distribution width: A simple parameter with multiple clinical applications. Crit Rev Clin Lab Sci. 2015;52(2):86-I05. [CrossRef]

19. Chen GP, Huang $Y$, Yang $X$, Feng JF. A nomogram to predict prognostic value of red cell distribution width in patients with esophageal cancer. Mediators Inflamm. 2015:854670. [CrossRef]

20. Riedl J, Posch F, Konigsbrugge $O$, et al. Red cell distribution width and other red blood cell parameters in patients with cancer: Association with risk of venous thromboembolism and mortality. PLoS One. 2014;9(I0):ell|440. [CrossRef]

21. Liu H, Liu G, Bao Q, et al. The baseline ratio of neutrophils to lymphocytes is associated with patient prognosis in rectal carcinoma. J Gastrointest Cancer. 2010;4I(2):II6-I20. [CrossRef]

22. Yamanaka $T$, Matsumoto $S$, Teramukai $S$, Ishiwata $R$, Nagai $Y$, Fukushima $M$. The baseline ratio of neutrophils to lymphocytes is associated with patient prognosis in advanced gastric cancer. Oncology. 2007;73(3-4):215-220. [CrossRef]

23. Liu CL, Lee JJ, Liu TP, Chang YC, Hsu YC, Cheng SP. Blood neutrophil-to-lymphocyte ratio correlates with tumor size in patients with differentiated thyroid cancer. J Surg Oncol. 2013;107(5):493-497. [CrossRef]

24. Ozturk K, Akyildiz NS, Uslu M, Gode S, Uluoz U. The effect of preoperative neutrophil, platelet and lymphocyte counts on local recurrence and survival in early-stage tongue cancer. Eur Arch Otorhinolaryngol. 2016;273(12):4425-4429. [CrossRef]

25. Chen S, Guo J, Feng C, Ke Z, Chen L, Pan Y. The preoperative platelet-lymphocyte ratio versus neutrophil-lymphocyte ratio: Which is better as a prognostic factor in oral squamous cell carcinoma? Ther Adv Med Oncol. 2016;8(3):160-167. [CrossRef]

26. Ekici NY, Kuran G. Parotis Bezi Tümörü Olan Hastalarda Benign Ve Malign Kitlelerin Ayırıcı Tanısında Sistemik Inflamatuar Belirteçlerin Önemi. KBB-Forum. 2019;18(2):I0I-I06.

27. Sut A, Pytel M, Zadrozny M, Golanski J, Rozalski M. Polyphenolrich diet is associated with decreased level of inflammatory biomarkers in breast cancer patients. Rocz Panstw Zakl Hig. 2019;70(2):177-184.

28. Valiathan R, Ashman $M$, Asthana D. Effects of ageing on the immune system: Infants to elderly. Scand J Immunol. 20l6;83(4):255-266. [CrossRef]

29. Valiathan R, Deeb K, Diamante M, Ashman M, Sachdeva N, Asthana $D$. Reference ranges of lymphocyte subsets in healthy adults and adolescents with special mention of $T$ cell maturation subsets in adults of South Florida. Immunobiology. 2014;219(7):487496. [CrossRef]

30. Yaman A, Cetiner S, Kibar F, Tasova Y, Seydaoglu G, Dundar $\mathbb{H}$. Reference ranges of lymphocyte subsets of healthy adults in Turkey. Med Princ Pract. 2005;14(3):189-193. [CrossRef]

31. Hoffmann JJ, Nabbe KC, van den Broek NM. Effect of age and gender on reference intervals of red blood cell distribution width (RDW) and mean red cell volume (MCV). Clin Chem Lab Med. 2015;53(I2):2015-2019.

32. Li J, Chen Q, Luo X, et al. Neutrophil-to-lymphocyte ratio positively correlates to age in healthy population. J Clin Lab Anal. 2015;29(6):437-443. [CrossRef] 